\title{
Case Report \\ Use of the Bonfils Intubation Fiberscope in Patients with Limited Mouth Opening
}

\author{
Nabil A. Shollik, ${ }^{1}$ Sami M. Ibrahim, ${ }^{1}$ Ahmed Ismael, ${ }^{1}$ Vanni Agnoletti, ${ }^{2}$ \\ Emanuele Piraccini, ${ }^{2}$ and Ruggero Massimo Corso ${ }^{2}$ \\ ${ }^{1}$ Anesthesia Department, HMC-Weill Cornell Medical College, P.O. Box 24144, Doha, Qatar \\ ${ }^{2}$ Anaesthesia and Intensive Care Section, Department of Emergency, G.B. Morgagni-Pierantoni Hospital, viale Forlanini 34,47100 \\ Forli, Italy
}

Correspondence should be addressed to Vanni Agnoletti, vanni.agnoletti@me.com

Received 6 June 2012; Accepted 2 August 2012

Academic Editors: S. Faenza and E. W. Nielsen

Copyright (C) 2012 Nabil A. Shollik et al. This is an open access article distributed under the Creative Commons Attribution License, which permits unrestricted use, distribution, and reproduction in any medium, provided the original work is properly cited.

\begin{abstract}
Airway management of patients with very limited mouth opening remains a challenge for the anaesthetist. We describe the use of the Bonfils Intubation Fiberscope for awake intubation in two patients with a very limited mouth opening. In the first case, a 60 -year-old $80 \mathrm{~kg}$ female, scheduled for a right modified radical mastectomy for infiltrating ductal carcinoma $(15 \mathrm{~mm}$ mouth opening, a short thick neck, limited neck extension, and a Mallampati class 4 airway), the Bonfils was advanced via the retromolar technique. In the second patient, a 34-year-old male, scheduled for a surgical tracheotomy for right tonsillar cancer, due to a neoplastic infiltration of the right temporomandibular joint ( $7 \mathrm{~mm}$ mouth opening and limited neck movement), the Bonfils was advanced using the midline approach. The Bonfils is a reusable, rigid, straight fiberoptic device with a curved tip, is $5 \mathrm{~mm}$ in diameter, and has several advantages: it is quick and easy to use, more cost effective than a flexible fiberscope, and is safe in expert hands, thanks to its smaller diameter. Our conclusion is that awake BIF intubation is a reliable, atraumatic, and well-tolerated procedure to secure a safe airway in patients with a limited mouth opening.
\end{abstract}

\section{Introduction}

Airway management of patients with very limited mouth opening remains a challenge for the anaesthetist. The standard approach for predicted difficult intubation is awake intubation with a flexible fiberscope [1]. This procedure however, may prove very difficult in patients with a distorted airway; it requires a lot of practice and is quite expensive [2].

\section{Case Presentation}

We describe the use of the Bonfils Intubation Fiberscope (BIF) (Karl Storz Endoscope, Tuttlingen, Germany) for awake intubation in two patients with a very limited mouth opening. The first was a 60-year-old $80 \mathrm{~kg}$ female (body mass index, BMI: $33 \mathrm{~kg} \mathrm{~m}^{-2}$ ) with an American Society of Anaesthesiology (ASA) physical status II, scheduled for a right modified radical mastectomy for infiltrating ductal carcinoma. Preoperative examination revealed a $15 \mathrm{~mm}$ mouth opening, a short thick neck, limited neck extension, and a Mallampati class 4 airway. In the operating room, she received midazolam $2 \mathrm{mg}$ IV and a topical anaesthesia of the oropharynx with lidocaine $10 \%$. The patient was administered oxygen $\left(4 \mathrm{~L} \mathrm{~min}^{-1}\right)$ for 5 minutes and then through the side port of BIF. The BIF (preloaded with a $7.0 \mathrm{~mm}$ cuffed tracheal tube, TT) was advanced via the retromolar technique. When it was positioned in front of the vocal cords, the TT was advanced over the scope. End-tidal capnography confirmed the tracheal placement and then a routine IV induction was performed. The second patient was a 34-year-old male (BMI: $16 \mathrm{~kg} \mathrm{~m}^{-2}$ ) with an ASA physical status I, scheduled for a surgical tracheotomy for right tonsillar cancer. The airway evaluation revealed a limited mouth opening $(7 \mathrm{~mm})$ due to a neoplastic infiltration of the right temporomandibular joint, as well as limited neck movement. Topical anaesthesia of the oropharynx using 


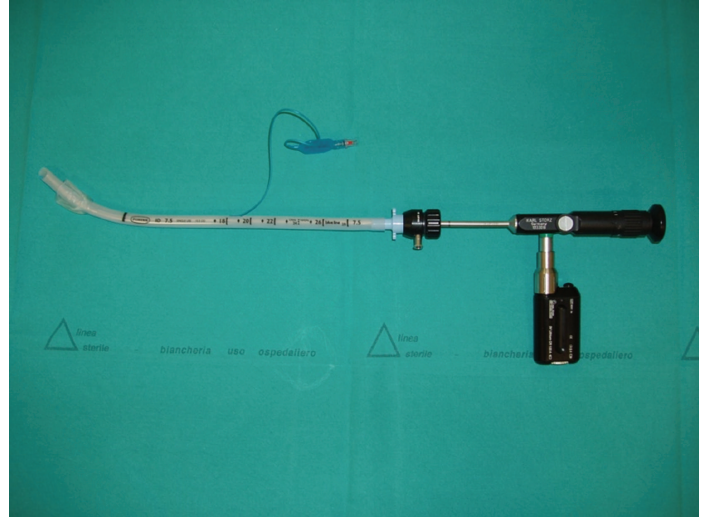

(a)

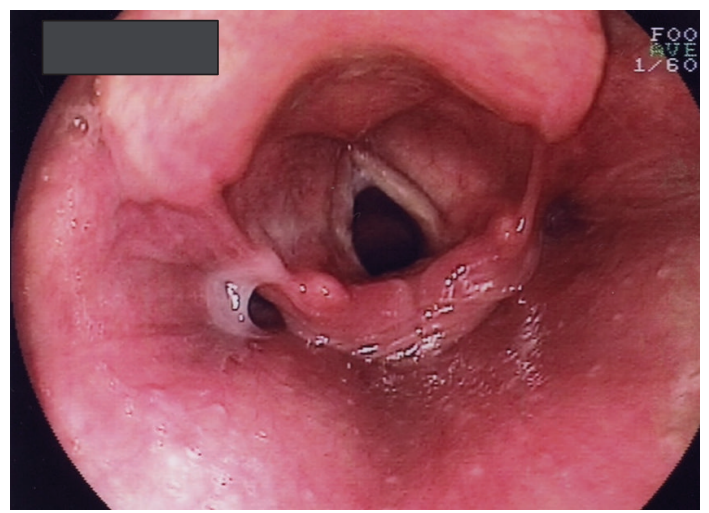

(c)

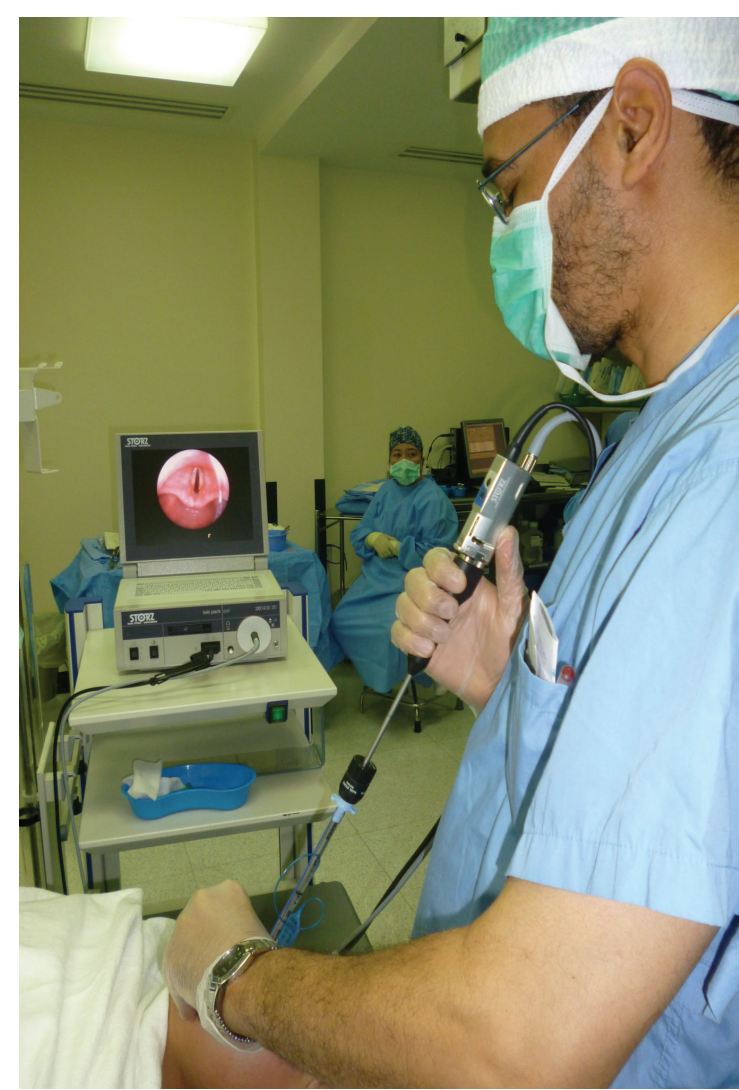

(b)

Figure 1: (a) Battery-powered Bonfils Intubation Fiberscope armed with an $7.5 \mathrm{~mm}$ inner diameter endotracheal tube, (b) intubation with a Bonfils intubation fiberscope. The video camera is attached at the eyepiece of the scope, (c) an endoscopic view of laryngeal aditus using Bonfils Intubation Fiberscope.

lidocaine $10 \%$ spray and local laryngeal anaesthesia by cricothyroid injection of $3 \mathrm{~mL}$ of lidocaine $2 \%$ were administered. He received IV fentanyl $(100 \mu \mathrm{g})$ and supplemental oxygen $\left(4 \mathrm{~L} \mathrm{~min}^{-1}\right)$ for 5 minutes, then through the side port of the BIF. A BIF preloaded with a $6 \mathrm{~mm}$ cuffed TT was advanced using a midline approach. When the BIF was in front of the vocal cords, the TT was advanced over the scope into the trachea. After confirmation of correct placement by capnography, a routine IV induction of anaesthesia was performed.

\section{Discussion}

The BIF is a reusable, rigid, straight fiberoptic device with a curved tip and is $5 \mathrm{~mm}$ in diameter (Figure 1). It has been successfully used in patients with both predicted and unpredicted difficult airways $[3,4]$. It has several advantages: it is quick and easy to use, more cost effective than a flexible fiberscope, and is safe in expert hands [5].

It has a distinct advantage over the latest videolaryngoscopes, which are larger in size and therefore, for patients with a poor mouth opening, it may be difficult to insert the blades or to pass the TT. The BIF, thanks to its smaller diameter, facilitates intubation in such patients.
Our conclusion is that awake BIF intubation is a reliable, atraumatic, and well-tolerated procedure to secure a safe airway in patients with a limited mouth opening.

\section{Disclosure}

This is a statement confirming that all authors have read and accept the "Terms and Conditions for Anaesthesia and Intensive Care submissions" as outlined in the online submission process.

\section{Conflict of Interests}

The authors declare no conflict of interests.

\section{Authors' Contribution}

N. A. Shallik was involved in the concept and design, the acquisition and interpretation of data, drafting of the paper, and its final approval. S. M. Ibrahim was involved in the concept and design, drafting of the paper, and its final approval. A. Ismael was involved in the concept and design, drafting of the paper, and its final approval. V. Agnoletti was involved in the critical revision of the paper and its final 
approval. E. Piraccini was involved in the critical revision of the paper and its final approval. R. M. Corso was involved in the critical revision of the paper, and its final approval.

\section{References}

[1] R. A. Caplan, J. L. Benumof, F. A. Berry et al., "Practice guidelines for management of the difficult airway: an updated report by the American Society of Anesthesiologists Task Force on Management of the Difficult Airway," Anesthesiology, vol. 98, no. 5, pp. 1269-1277, 2003.

[2] A. Ovassapian, S. J. Yelich, M. H. M. Dykes, and E. E. Brunner, "Fiberoptic nasotracheal intubation-incidence and causes of failure," Anesthesia and Analgesia, vol. 62, no. 7, pp. 692-695, 1983.

[3] J. E. Mazères, A. Lefranc, C. Cropet et al., "Evaluation of the Bonfils intubating fibrescope for predicted difficult intubation in awake patients with ear, nose and throat cancer," European Journal of Anaesthesiology, vol. 28, no. 9, pp. 646-650, 2011.

[4] C. Rudolph, A. Henn-Beilharz, R. Gottschall, J. Wallenborn, and L. Schaffranietz, "The unanticipated difficult intubation. Rigid or flexible endoscope?” Minerva Anestesiologica, vol. 73, no. 11 , pp. 567-574, 2007.

[5] A. Webb, H. Kolawole, S. Leong, T. E. Loughnan, T. Crofts, and C. Bowden, "Comparison of the Bonfils and Levitan optical stylets for tracheal intubation: a clinical study," Anaesthesia and Intensive Care, vol. 39, no. 6, pp. 1093-1097, 2011. 


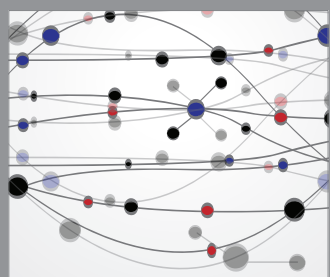

The Scientific World Journal
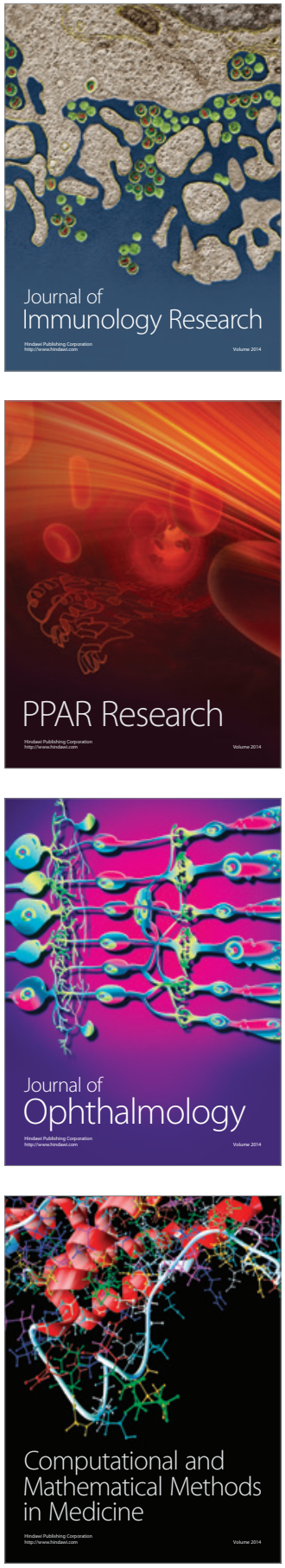

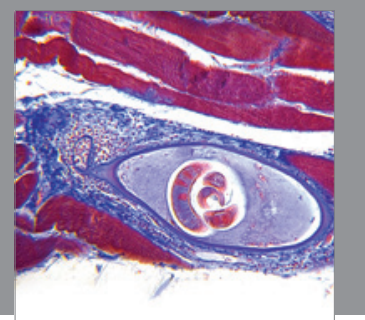

Gastroenterology

Research and Practice
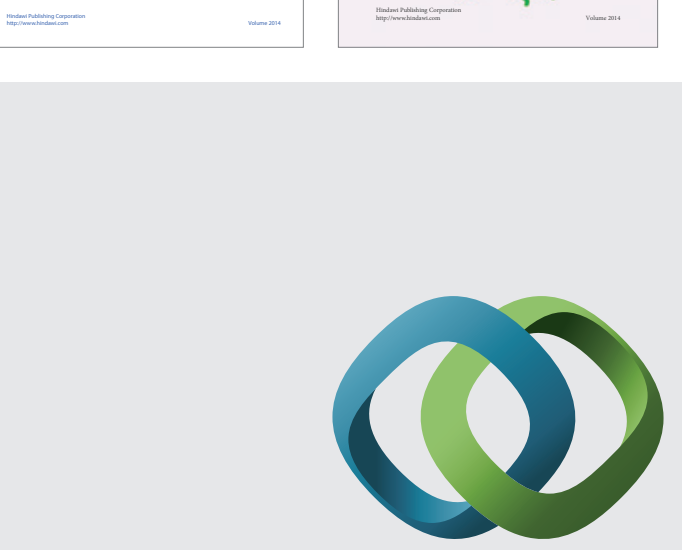

\section{Hindawi}

Submit your manuscripts at

http://www.hindawi.com
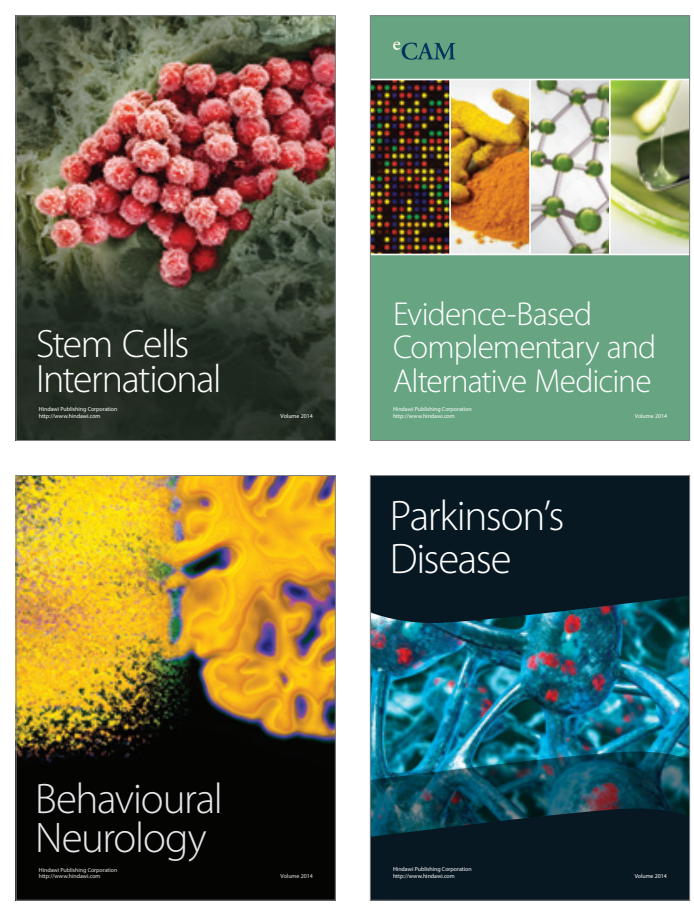

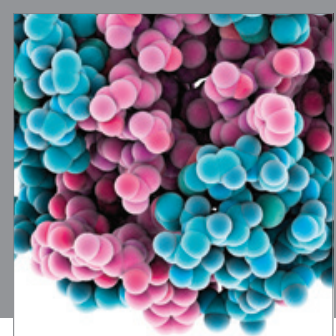

Journal of
Diabetes Research

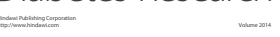

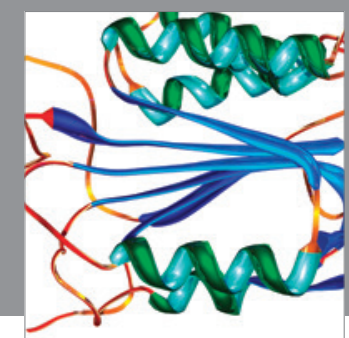

Disease Markers
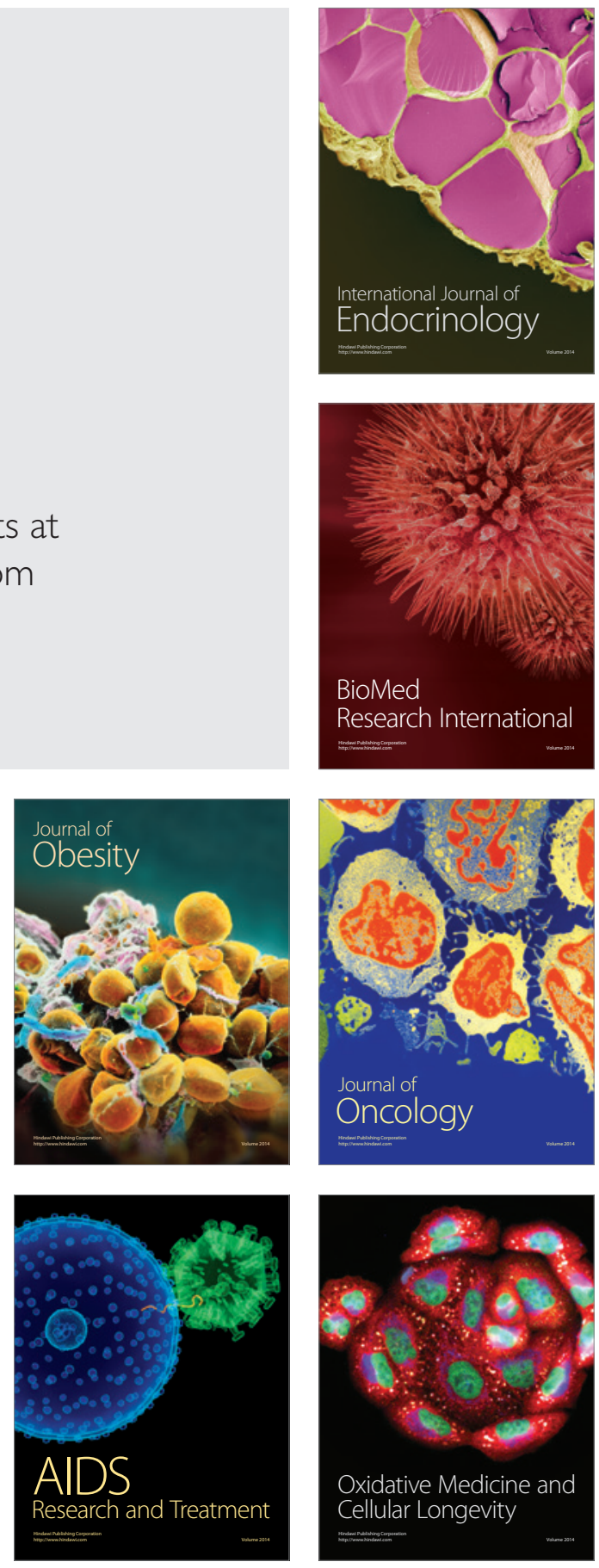